\title{
ANALISIS PERENCANAAN PAJAK MELALUI PENYUSUTAN AKTIVA TETAP DAN PERHITUNGAN PAJAK BADAN PDAM TIRTA JENEBERANG KABUPATEN GOWA
}

\author{
Andi Arifwangsa A ${ }^{1}$, Saida Said ${ }^{2}$, Ulfa Husain ${ }^{3}$ \\ Universitas Muhammadiyah Makassar \\ e-mail: ${ }^{1}$ Andiariefky@unismuh.ac.id, ${ }^{2}$ Saida.said@unismuh.ac.id ${ }^{3}$ muh.adil@unismuh.ac.id
}

\begin{abstract}
In this research aims to whether with tax planning through the depreciation of fixed assets on the company can minimize the tax burden. This research uses a secondary method on the PDAM Tirta Jeneberang Regency Gowa. Data used in this research is data on the annual report of the PDAM Tirta Jeneberang Regency Gowa. Data collection is done by collecting financial report data in the company year that is a sample of the research of PDAM Company Tirta Jeneberang Kabupaten Gowa. The Data is collected by conducting a documentation method. From the analysis conducted on the implementation of tax planning applied by the company with the prevailing taxation law apparently the company does not commit violations and still follow all applicable regulations.
\end{abstract}

Key words: Tax, Tax planning, minimizing tax expenses

\begin{abstract}
Abstrak
Dalam penelitian ini bertujuan untuk apakah dengan perencanaan pajak melalui penyusutan aktiva tetap pada perusahaan dapat meminimalkan beban pajak. Penelitian ini menggunakan metode sekunder pada PDAM Tirta Jeneberang Kabupaten Gowa. Data yang digunakan dalam penelitian ini adalah data Laporan Tahunan PDAM Tirta Jeneberang Kabupaten Gowa. Pengumpulan data dilakukan dengan cara mengumpulkan data laporan keuangan pada tahun perusahaan yang menjadi sampel penelitian yaitu perusahaan PDAM Tirta Jeneberang Kabupaten Gowa. Data tersebut dikumpulkan dengan cara melakukan metode dokumentasi. Dari analisis yang dilakukan terhadap penerapan perencanaan pajak yang diterapkan oleh perusahaan dengan Undang-Undang Perpajakan yang berlaku ternyata perusahaan tidak melakukan pelanggaran dan masih mengikuti semua peraturan yang berlaku.
\end{abstract}

Kata kunci : Pajak, Perencanaan Pajak, Meminimalkan Beban Pajak 


\section{PENDAhUluAN}

Pajak merupakan sumber penerimaan utama negara yang digunakan untuk membiayai pengeluaran pemerintah dan pembangunan. Hal ini tertuang dalam Anggaran Penerimaan dan Belanja Negara (APBN) dimana penerimaan pajak merupakan penerimaan dalam negeri yang terbesar. Target Pendapatan Negara dalam APBN tahun 2016 ditetapkan sebesar Rp1.822,5 triliun, atau Rp25,6 triliun lebih rendah dari yang diusulkan dalam RAPBN Tahun Anggaran 2016. Target Pendapatan Negara tersebut bersumber dari Penerimaan Perpajakan sebesar Rp1.546,7 triliun dan Penerimaan Negara Bukan Pajak sebesar Rp273,8 triliun (rasio penerimaan negara terhadap PDB atau tax ratio dalam tahun 2016 sebesar 13,11 persen).

Perencanaan pajak (tax planning) itu sendiri menurut Moh.Zain (2012: 43) dalam manajemen perpajakan, adalah "proses mengorganisasi usaha wajib pajak atau kelompok wajib pajak sedemikian rupa sehingga utang pajaknya, baik pajak penghasilan maupun pajak-pajak lainnya, berada dalam posisi yang paling minimal, sepanjang hal ini dimungkinkan baik oleh ketentuan peraturan perundang-undangan perpajakan maupun secara komersial". Sesungguhnya antara penghindar pajak dan penyelundupan pajak terdapat perbedaan yang fundamental, akan tetapi kemudian perbedaan tersebut menjadi kabur, baik secara teori maupun aplikasinya. Secara konseptual, justru dalam menentukan perbedaan antara penghindar pajak dan penyelundupan pajak, kesulitannya terletak pada ketentuaan perbedaannya, akan tetapi berdasarkan konsep perundang-undangan, garis pemisahnya adalah antara melanggar undangundang (unlawful) dan tidak melanggar undang-undang (lawful).

Mengingat pentingnya perencanaan pajak bagi pemenuhan kewajiban pajak suatu perusahaan, disatu sisi, dan penghematan pajak bagi oprasional perusahaan sehari-hari, disisi lain, maka penulis tertarik untuk mengadakan penelitian melalui perencanaan pajak melalui penyusutan aktiva tetap, dan perhitungan besarnya pajak terhutang wajib pajak Badan setelah penyusutan tersebut. Penelitian dilakukan pada PDAM Tirta Jeneberang Kabupaten Gowa.

\section{TINJUAN PUSTAKA}

\section{Pajak}

Pengertian Pajak itu sendiri menurut Soemitro (2011), seperti yang diuraikan dalam Dasar-Dasar Hukum Pajak pendapatan, adalah sebagai berikut: "Pajak adalah iuran rakyat kepada kas Negara atau peralihan kekayaan dari sector swasta ke sektor pemerintah dengan tiada mendapat imbal jasa timbal yang langsung dapat ditunjuk dan yang digunakan untuk membiayai pengeluaran umum".

\section{Perencanaan Pajak}

Secara garis besar pengertian Perencanaan Pajak (Tax Planning) menurut Zain (2007) adalah merupakan tindakan penstrukturan yang terkait dengan konsekuiensi potensi pajaknya, yang tekanannya kepada pengendalian setiap transaksi yang ada konsekuensi pajaknya.

Adapun pengertian Perencanaan Pajak (Tax Planning) menurut Nur Hidayat dalam artikel Tax PlanningBukan Untuk Hindari Pajak (2012) menyebutkan bahwa: "Perencanaan Pajak (Tax Planning) adalah upaya menekan jumlah kewajiban pajak dengan cara legal".

\section{METODE}

\section{Pendekatan Penelitian}

Pendekatan yang digunakan dalam penelitian ini adalah pendekatan kuantitatif dengan ilmiah yaitu berfikit untuk memecahkan masalah secara sistematis, empiris, dan terkontrol yang dengan angka-angka. Penelitian ini dilakukan pada PDAM Tirta Jeneberang Kabupaten Gowa.Waktu penelitian untuk memperoleh data kurang lebih dua (2) bulan yaitu Mei sampai Juni 2017.

Tabel 1. Lapisan Penghasilan Kena Pajak Wajib Pajak Badan Dalam Negeri dan Bentuk Usaha Tetap (BUT)

\begin{tabular}{ll}
\hline Lapisan Penghasilan Kena Pajak & Tarif Pajak \\
\hline Sampai dengan Rp 50.000.000,00 (lima puluh juta rupiah) & $\begin{array}{l}10 \% \\
\text { (sepuluh persen) }\end{array}$ \\
\hline $\begin{array}{l}\text { Di atas Rp 50.000.000,00 (lima puluh juta rupiah) s.d Rp 100.000.000,00 (seratus juta } \\
\text { rupiah) }\end{array}$ & $\begin{array}{l}15 \% \\
\text { (lima belas persen) }\end{array}$ \\
\hline
\end{tabular}


Dilakukan penelitian laporan keuangan terhadap perusahaan yang menjadi objek yaitu PDAM Tirta Jeneberang Kabupaten Gowa. Strategi perencanaannya adalah menghitung penyusutan aktiva tetap yang sudah memenuhi persyaratan. Untuk menghitung penyusutan aktiva tetapnya digunakan metode saldo menurun yaitu:

Penyusutan $=[(100 \%$ : Umur Ekonomis $) \times 2]$ $\mathrm{x}$ Nilai Perolehan / Nilai Buku

\section{HASIL DAN PEMBAHASAN}

\section{Hasil}

Berikut adalah perbandingan Laporan Laba Rugi fiskal sebelum dan sesudah Perencanaan Pajak PDAM Tirta Jeneberang Kabupaten Gowa yang dapat dilihat pada tabel di bawah ini : Tabel 3 adalah Laporan Laba Rugi PDAM Tirta Jeneberang Kabupaten Gowa untuk tahun yang berakhir pada tanggal 31 Desember 2013 setelah Tax Planning.

Tabel 2. PDAM Tirta Jeneberang Kabupaten Gowa Laporan Laba Rugi per 31 Desember 2013

\begin{tabular}{|c|c|}
\hline Penjualan & 2.723 .863 .787 \\
\hline Beban Pokok Penjualan & 1.682 .722 .369 \\
\hline Laba Kotor Beban Usaha & 1.041 .141 .418 \\
\hline \multicolumn{2}{|l|}{ Beban Penjualan dan distribus } \\
\hline Pengangkutan dari bongkar muat & 67.906 .277 \\
\hline Gaji, Upah dan Tunjangan & 25.3500 .667 \\
\hline Pemasaran dan promise & 12.430 .542 \\
\hline Perjalanan Dinas & 2.877 .427 \\
\hline Perlengkapan Kantor & 1.546 .973 \\
\hline Perbaikan dan Pemeliharaan & 840.263 \\
\hline Lain-Lain & 2.645 .020 \\
\hline Jumlah Beban Penjualan & 113.597 .169 \\
\hline \multicolumn{2}{|l|}{ Beban Umum dan administrasi } \\
\hline Gaji, Upah dan Tunjangan & 113.571 .456 \\
\hline Program Kemitraan dan Bina & 9.189 .537 \\
\hline Lingkungan & 9.782 .337 \\
\hline Pajak dan Retribusi & 8.619 .812 \\
\hline Perjalanan Dinas & 7.310 .321 \\
\hline Rapat & 5.767 .466 \\
\hline Bahan Bakar, Listrik, dan Minyak & 5.665 .245 \\
\hline Pelumas & 5.436 .503 \\
\hline Pembinaan Karyawan & 4.146 .019 \\
\hline Penyusutan & 4.043 .679 \\
\hline Perbaikan dan Pemeliharaan & 2.419 .658 \\
\hline Perlengkapan Kantor & 1.561 .158 \\
\hline Jasa Profesional & 1910.090 \\
\hline Sewa & 6.416 .267 \\
\hline Asuransi & 185.143 .548 \\
\hline Lain-lain & 298.739 .737 \\
\hline Jumlah Beban Administrasi dan Umum & 742.401 .681 \\
\hline Jumlah Beban Usaha & 10.289 .923 \\
\hline LABA USAHA & - \\
\hline (Beban) Penghasilan Lain-lain & $(10.162 .548)$ \\
\hline Penghasilan Bunga & $(8.341 .914)$ \\
\hline Laba Penjualan Aset Tetap & 4.099 .057 \\
\hline \multicolumn{2}{|l|}{ Beban Bunga } \\
\hline Kerugian selisih kurs-bersih Lain-lain bersih & $(4.135 .472)$ \\
\hline Jumlah (beban) penghasilan lain-lain bersih & 736.266 .209 \\
\hline \multicolumn{2}{|l|}{ LABA SEBELUM PAJAK } \\
\hline Perbedaan Permanen & 49.700 .993 \\
\hline Beban yang tidak dapat dikurangkan & $(10.763 .567)$ \\
\hline Pendapatan yang telah dikenakan & 38.929 .044 \\
\hline
\end{tabular}




\begin{tabular}{ll}
\hline Pajak Penghasilan Final & 13.446 .964 \\
\hline Pemeliharaan mobil dinas & 4.460 .301 \\
\hline Perbedaan temporer : & \\
\hline Penyisihan untuk jasa produksi dan intensif & $(2.119 .646)$ \\
\hline Kewajiban imbalan kerja & 476.224 \\
\hline Penyisihan persediaan utang dan bergerak lambat & 21.501 .119 \\
\hline Penyisihan penurunan nilai piutang Perbedaan penyusutan komersial dan fiskal & $659.673)$ \\
\hline Aset sewa & 2.216 .613 \\
\hline Penyisihan biaya promosi penjualan & 34.891 .476 \\
\hline Jumlah & 812.068 .729 \\
\hline \multicolumn{1}{c}{ Sumber : PDAM Tirta Jeneberang Kabupaten Gowa (telah diolah di Pembahasan) }
\end{tabular}

Berikut adalah perhitungan PPh badan untuk melihat perbedaan laba bersih setelah pajak sebelum melakukan perencanaan pajak dan setelah perencanaan pajak.

Sebelum perencanaan pajak PPh Terhutang tahun 2013:

Pajak kini $25 \%$ x Rp 813.607.824=

Rp 203.401.950.000

Manfaat beban pajak tangguhan $=$

(Rp 8.722.869.000)

Jumlah Taksiran Pajak Penghasilan $=$

Rp 194.679.087.000

Laba Bersih Setelah Pajak:

Laba Bersih Komersil = Rp 738.266.209.000

Pajak Penghasilan $\quad=$ Rp 194.679.087.000)

Laba Setelah Pajak $\quad=$ Rp 543.587.122.000

2013:

Setelah Perencanaan Pajak PPh terhutang

Pajak Kini 25\% x Rp 812.086.729=
Rp 203.021.682.000

Manfaat Beban Pajak Tangguhan $=$

Rp 8.722.869.000

Jumlah Taksiran Pjak Penghasilan =

Rp 194.298.813.000

Laba Bersih Setelah Pajak:

Laba Bersih Komersil = Rp 738.266.209.000

Pajak Penghasilan $\quad=(\operatorname{Rp} 194.298 .813 .000)$

Laba Setelah Pajak $\quad=$ Rp 543.967.396.000

Jadi Penghematan Pajak Yang Dapat diperoleh Perusahaan:

Laba Setelah Pajak (sebelum Tax planning) $=$

Rp 543.967.396.000

Laba setelah Pajak (setelah Tax planning) $=$

Rp 543.587.122.000

Penghematan Pajak =

Rp 380.274.000

Tabel 3. Kredit Pajak PPh Pasal 22 dan 25 (setelah tax planning) Tinjauan Pembayaran Utang Pajak PDAM Tirta Jeneberang Kabupaten Gowa

\begin{tabular}{ll}
\hline Keterangan & 2013 \\
\hline Penghasilan Kena Pajak & $\mathrm{Rp} \mathrm{812.086.729.000}$ \\
\hline PPh Terhutang & $\mathrm{Rp} \mathrm{203.021.682.000}$ \\
\hline Kredit Pajak: & $\mathrm{Rp} \mathrm{153.215.165.000}$ \\
\hline PPh Pasal 22 dan 23 & $\operatorname{Rp~49.506.517.000~}$ \\
\hline PPh Terhutang Tahun 2013 &
\end{tabular}

Tabel 5. Hasil Perencanaan Pajak PDAM Tirta Jeneberang Kabupaten Gowa

\begin{tabular}{llll}
\hline \multirow{2}{*}{ Keterangan } & $\begin{array}{l}\text { Sebelum Tax } \\
\text { Planning }(\text { Rp })\end{array}$ & $\begin{array}{l}\text { Setelah Tax } \\
\text { Planning }(\text { Rp })\end{array}$ & \multirow{2}{*}{ Penghematan (RP) } \\
\hline Beban Pajak & 543.967 .396 .000 & 543.587 .122 .000 & 380.274 .000 \\
\hline PPh Pasal 22 dan 25 & 50.186 .791 .000 & 49.806 .517 .000 & 380.274 .000 \\
\hline
\end{tabular}

Sumber: PDAM Tirta Jeneberang Kabupaten Gowa (telah diolah)

Maka penghematan pajak yang dapat diperoleh karena adanya perencanaan pajak adalah sebesar Rp 380.274.000. Laba bersih setelah pajak yang siap dibagikan sebagai deviden adalah laba bersih komersil dikurangi pajak penghasilan yaitu Rp 543.587.122.000 (sebelum tax planning) dan Rp 543.967.396.000 (setelah tax planning). Penghematan ini terjadi karena ditiadakannya mobil dinas sebagai fasilitas, melainkan digunakan seperlunya hanya untuk keperluan oprasional perusahaan saja, 
sehingga biaya pemeliharaan yang telah dikoreksi sebesar Rp 1.521.095.000.

Setelah perusahaan menetapkan perencanaan pajak yang menghasilkan PPh terutang untuk tahun2013 sebesar Rp 203.021.658.000. Secara otomatis membantu menurunkan $\mathrm{PPh}$ terutang perusahaan. PPh terutang perusahaan sebelum menerapkan perencanaan pajak sebesar $\mathrm{Rp}$ 50.186.791.000 turun menjadi $\mathrm{Rp}$ 49.806.517.000. Sehingga bisa dilihat dengan jelas adanya efisiensi penghematan sebesar Rp 380.274.000. Dalam menerapkan strategi pelaksanaan pajak, perusahaan memiliki beberapa kebijakan-kebijakan akuntansi yang dijadikan acuan. Selain itu, perusahaan juga melakukan beberapa langkah seperti, memaksimalkan penghasilan yang dikecualikan melalui pemaksimalan penghasilan bunga dan sewa gedung, memaksimalkan biaya fiskal, dan meminimalkan biaya yang tidak diperkenankan sebagai pengurangan. Kemudian perusahaan juga lebih memilih menggunakan metode penyusutan saldo menurun. Dari analisis yang dilakukan terhadap penerapan perencanaan pajak yang diterapkan oleh perusahaan dengan Undang-Undang Perpajakan yang berlaku ternyata perusahaan tidak melakukan pelanggaran dan masih mengikuti semua peraturan yang berlaku. Kemudian dapat pula dilihat dari hasil penerapan perencanaan pajak yang meniadakan fasilitas mobil dinas ternyata bisa mengurangi biaya pemeliharaan bagi perusahaan yang akan menjadi pengurang penghasilan kena pajak. Sehingga perencanaan pajak yang dilakukan oleh PDAM Tirta Jeneberang Kabupaten Gowa akan meminimalkan Pajak Penghasilan Terutang yang akan dibayarkan kepada Pemerintah.

Hasil penelitian ini memberikan bukti bahwa perencanaan pajak yang optimal dapat menghemat Pajak Penghasilan Badan (Zain, 2003 Suandy, 2006) yang mengemukakan pendapat bahwa bagaimana pengendalian tersebut dapat mengefisienkan jumlah pajaknya yang akan di transfer ke Pemerintah serta penelitian terhadap peraturan perpajakan agar dapat diseleksi jenis tindakan penghematan pajak yang akan dilakukan. Setelah melakukan penelitian pada perusahaan PDAM Tirta Jeneberang Kabupaten Gowa penulis menemukan bahwa dengan melakukan perencanaan pajak melalui penyusutan aktiva tetap dapat membantu untuk meminimalkan beban pajak, sehingga dapat disarankan kepada perusahaan yang diteliti maupun perusahaan lain agar melakukan perencanaan pajak melalui penyusutan aktiva tetap karena tidak melanggar Undang-Undang Perpajakan.

\section{KESIMPULAN DAN SARAN}

\section{Kesimpulan}

Berdasarkan hasil penelitian dan pembahasan mengenai perencanaan pajak melalui penyusutan aktiva tetap dan besarnya penghematan pajak terhutang Wajib Pajak Badan PDAM Tirta Jeneberang Kabupaten Gowa dapat disimpulkan bahwa perusahaan yang diteliti menerapkan perencanaan pajak melalui penyusutan aktiva tetap dengan cara menghitung penyusutan aktiva tetap dan dampaknya bagi pajak sebelum dilakukan penyusutan dan setelah dilakukan penyusutan aktiva tetap. Dalam menerapkan strategi pelaksanaan pajak, perusahaan memiliki beberapa kebijakan-kebijakan akuntansi yang dijadikan acuan. Selain itu, perusahaan juga melakukan beberapa langkah seperti, memaksimalkan penghasilan yang dikecualikan melalui pemaksimalan penghasilan bunga dan sewa gedung, memaksimalkan biaya fiskal, dan meminimalkan biaya yang tidak diperkenankan sebagai pengurangan. Kemudian perusahaan juga lebih memilih menggunakan metode penyusutan saldo menurun.

a. Dari analisis yang dilakukan terhadap penerapan perencanaan pajak yang diterapkan oleh perusahaan dengan UndangUndang Perpajakan yang berlaku ternyata perusahaan tidak melakukan pelanggaran dan masih mengikuti semua peraturan yang berlaku.

b. Perusahaan menggunakan metode saldo menurun untuk menghitung penyusutan aktiva tetap

\section{Saran}

Berdasarkan hasil penelitian dan pembahasan, maka peneliti memberikan saran sebagai berikut:

a. Bagi peneliti selanjutnya Disarankan untuk menambah jumlah sampel dalam penelitian agar hasil yang didapat lebih baik.

b. Bagi perusahaan agar mempertimbangkan untuk melakukan perencanaan pajak melalui Penyusutan Aktiva Tetap karena dapat meminimalkan beban pajak, sehingga 
memberikan dampak positif terhadap perusahaan.

c. Bagi dunia Pendidikan dan pihak-pihak lain yang berkepentingan perlu diadakan penelitian-penelitian berikutnya, baik untuk industri lain yang sejenis maupun untuk industri lain yang tidak sejenis.

\section{REFERENSI}

Anastasia Diana \& Lilis Setiawan 2013. Perpajakan Teori dan Peraturan Terkini, Yogyakarta: Penerbit Andi.

Ayu Ernawati, Moch. Dzulkirom AR \& Devi Farah Azizah 2013. Analisis Tax Planning Sebagai Salah Satu Upaya Penghematan Pajak Penghasilan (PPh) Badan. Malang.

Bardjo Sugeng 2011. Pengaruh Perencanaan Pajak Terhadap Efisiensi Beban Pajak Penghasilan. Pasundan.

Christovint, Jullie J sondakh \& Harijanto Sabijono 2015. Evaluasi Perhitungan Penyusutan Aktiva Tetap Menurut Peraturan Perpajakan Serta Pengaruhnya Terhadap Pajak Penghasilan (PPh) Pada PT.Bank Tabungan Negara (Persero) Tbk Kantor Cabang Manado. Manado.

Dewa Ketut Wira Santana \& Made Gede WiraKusuma 2016. Pengaruh Perencanaan Pajak, Kepemilikan Manajerial dan Ukuran Perusahaan Terhadap Praktek Manajemen Laba. Bali.

Eva Anggarawati \& Rika Lidyah 2012. Evaluasi Perencanaan Pajak Untuk Meminimalkan Beban Pajak Pada PT.Bukit Asam (Persero) Tbk.

Erly Suandi 2011. Perencanaan Pajak.

Eliston Nadeak 2011. Pengaruh Revaluasi Aktiva Tetap Terhadap Penghematan Pajak PT. KABELINDO MURNI.

$\mathrm{http}: / /$ woocara.blogspot.com/2015/12/pengertia n-pajak-dan-unsurunsurpajak.html\#ixzz4YLnnEYgxintah

Lumban Turuan 2011. Akuntansi Pajak.

Mulyo Dwi Atmojo, Sri Mangesti Rahayu \& Otto Budihardjo 2014. Analisis Penerapan Perencanaan Pajak Pertambahan Nilai.

Nyoman Darmayasa \& Nyoman Sentosa Hardika 2011. Perencanaan Pajak Dari Aspek Rasio Total Bencharmaking,
Kebijakan Akuntansi, Dan Administrasi Sebagai Strategi Penghematan Pajak. Bali.

Nur Hidayat 2012. Artikel Tax Planning, Jakarta.

Priska Febriani Sahilatua \& Naniek Noviari 2013. Penerapan Perencanaan Pajak Penghasilan Pasal 21 sebagai Strategi Penghematan Pembayaran Pajak. Bali.

Surat Keputusan Mentri Keuangan NO.96/PMK.03/2009.

Susi Siswati 2011. Revaluasi Aset Tetap Berdasarkan Aspek Akuntansi PSAK 16 (Revisi 2011) dan Aspek Perpajakan. Yogyakarta. 